\title{
Influence of Efferent Stimulation on Acoustically Responsive Vestibular Afferents in the Cat
}

\author{
Michael P. McCue ${ }^{1,2, a}$ and John J. Guinan, Jr. ${ }^{1,2,3,4}$ \\ 'Eaton-Peabody Laboratory of Auditory Physiology, Department of Otolaryngology, Massachusetts Eye and Ear Infirmary, \\ Boston, Massachusetts 02114, ${ }^{2}$ Harvard-MIT Division of Health Science and Technology and Research Laboratory of \\ Electronics, and 3 Department of Electrical Engineering and Computer Science, Massachusetts Institute of Technology, \\ Cambridge, Massachusetts 02139, and 4Department of Otology and Laryngology, Harvard Medical School, Boston, \\ Massachusetts 02115
}

In the preceding article (McCue and Guinan, 1994) we described a class of vestibular primary afferent fibers in the cat that responds vigorously to sounds at moderately high sound levels. Like their cochlear homologs, vestibular afferents and their associated hair cells receive efferent projections from brainstem neurons. In this report, we explore efferent influences on the background activity and tone-burst responses of the acoustically responsive vestibular afferents.

Shock-burst stimulation of efferents excited acoustically responsive vestibular afferents; no inhibition was seen. A fast excitatory component built up within 100-200 msec of shock-burst onset and decayed with a similar time course at the end of each shock burst. During repeated $400 \mathrm{msec}$ shock bursts at 1.5 sec intervals, a slow excitatory component grew over 20-40 sec and then decayed, even though the shock bursts continued.

Efferent stimulation excited acoustically responsive vestibular afferents without appreciably changing an afferent's sound threshold or its average sound-evoked response. This evidence supports the hypothesis that excitation is due to efferent synapses on afferent fibers rather than on hair cells. Efferent stimulation enhanced the within-cycle modulation of afferent discharges evoked by a tone; that is, it increased the "AC gain." No appreciable change was noted in the degree of phase locking to low-frequency tones as measured by the synchronization index. Little or no improvement in the bidirectionality (linearity) of transduction was seen.

Vestibular afferent responses to tones normally had one peak per cycle; however, during efferent stimulation, two

\footnotetext{
Received Nov. 1, 1993; revised Mar. 15, 1994; accepted Apr. 6, 1994.

This work was submitted by M.P.M. to the Harvard-M.I.T. Division of Health Sciences and Technology in partial fulfillment of the requirements for the Sc.D. degree at the Massachusetts Institute of Technology and the M.D. degree at Harvard Medical School. We thank Drs. W. T. Peake, D. P. Corey, and N. Y.-S. Kiang for advice, manuscript comments, and criticism. Assistance in surgery was provided by L. W. Dodds, K. Jacob, and T. S. Liu, in engineering by F. Cardarelli, and in histology and fiber reconstruction by B. E. Norris. This research was partially supported by a grant from the Johnson and Johnson Company, and from NIH Grant R01 DC 00235. M.P.M. received support from NIH Training Grant T32 DC 00006, the Fairchild Foundation, and the Fulbright Commission.

Correspondence should be addressed to John J. Guinan, Jr., Eaton-Peabody Laboratory of Auditory Physiology, Massachusetts Eye and Ear Infirmary, 243 Charles Street, Boston, MA 02114.

- Present address: Department of Surgery, Massachusetts General Hospital, Boston, MA 02114.

Copyright (C) 1994 Society for Neuroscience $0270-6474 / 94 / 146071-13 \$ 05.00 / 0$
}

peaks per cycle were sometimes seen. We hypothesize that this is caused by two driving components acting at different sound phases with the components differentially affected by efferent activity.

We discuss the relationship of our findings to efferent influences on acoustic responses in cochlear afferent fibers. The acoustically responsive vestibular afferents provide a mammalian model for studying purely excitatory efferent effects in a hair cell system.

[Key words: saccule, otoliths, auditory system, mammalian sound reception, middle-ear muscles, cochlear nucleus]

Sensory organs of the mammalian inner ear are influenced by the activity of efferent neurons that have cell bodies in the brainstem (Fig. 1) (Galambos, 1956; Warr, 1975; Goldberg and Fernández, 1980). The only previous study of vestibular efferent stimulation in the cat suggested that efferents exert a weak inhibitory influence on the background spike activity of vestibular afferents (Dieringer et al., 1977). However, in an extensive study in the squirrel monkey, vestibular efferent stimulation was shown to exert an excitatory influence on $>99 \%$ of vestibular afferents (Goldberg and Fernández, 1980). An explanation advanced by Goldberg and Fernández (1980) for the apparent discrepancy between the species is that the small number of shocks used in the cat study was ineffective in activating the vestibular efferent system. One of our goals was to reexamine the influence of vestibular efferents in cats to determine whether vestibular efferents are consistently excitatory in mammals.

Although excitation is the predominant efferent effect found in vestibular afferents, efferents cause inhibition in most other sense organs. This inhibition has been attributed to direct efferent synapses on hair cells (Flock and Russell, 1973b; Klinke and Galley, 1974; Art et al., 1984; Gifford and Guinan, 1987). In the mammalian vestibular system, some efferent fibers synapse on hair cells and others synapse on afferent fibers (Fig. 2). One hypothesis to account for the different efferent effects is that excitation is produced by efferent endings on afferent fibers and that inhibition is produced by efferent endings on hair cells (Goldberg and Fernández, 1980). The results presented here are the first from an efferent system in which only excitation is present. Study of this systcm should help to determine whether the above hypothesis is correct.

The influence of efferent stimulation on the responses of vestibular afferents to mechanical stimuli has been well studied in only a few species, notably squirrel monkey (Goldberg and Fer- 


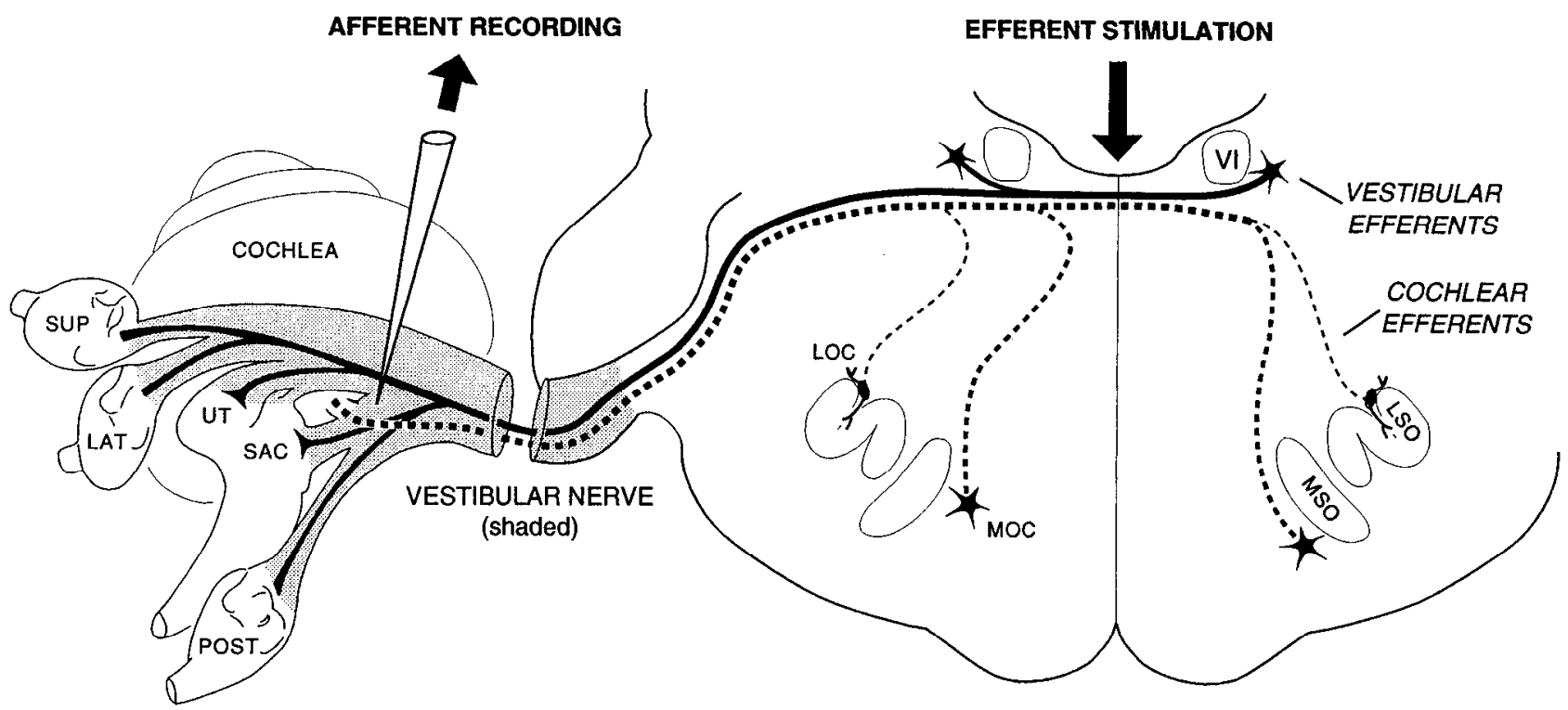

Figure 1. Schematic of the brainstem and labyrinth in the cat, showing the recording site in the inferior vestibular nerve (pipette) and the locations of vestibular efferent fibers (thick solid lines) and cochlear efferent fibers (dashed lines). The unshaded areas at left represent the cochlea and the vestibular apparatus with its two otolith organs $(S A C$, saccule; $U T$, utricle) and the cristae of its three semicircular canals $(S U P$, superior; $L A T$, lateral; POST, posterior). Vestibular efferents arise bilaterally near the abducens (VI) nuclei. Cochlear efferent neurons also arise bilaterally and are divided into two groups: the medial olivocochlear neurons $(M O C)$, which arise near the medial superior olive $(M S O)$, and the lateral olivocochlear neurons $(L O C)$, which arise near the lateral superior olive $(L S O)$ (Warr and Guinan, 1979). Cochlear efferents exit the brainstem in the vestibular nerve and reach the cochlea through the vestibulocochlear anastomosis, a fiber tract that leaves the vestibular nerve near the recording site. Both cochlear and vestibular efferents can be electrically stimulated at the floor of the fourth ventricle, where their axons travel in proximity.

nández, 1980) and toadfish (Boyle and Highstein, 1990). Results in both species suggest that the predominant effects of efferent activation are to elevate the background discharge rates and to reduce the response to mechanical stimuli. One rationale put forward for these effects is that with high-level mechanical stimuli, elevation of background rate prevents afferents from being silenced during any phase of the stimulus cycle. This allows the system to transduce stimuli linearly in both directions through increases and decreases in rate (Goldberg and Fernández, 1980; Boyle and Highstein, 1990).

Effects of efferent stimulation on vestibular afferent responses to mechanical stimuli have previously been examined only for low-frequency $(<50 \mathrm{~Hz})$ rotations and tilts - the adequate stimuli for organs of equilibrium and balance. We have recently studied a class of irregularly discharging vestibular afferents in the cat that respond to high-level, low-frequency sounds (McCue, 1993; McCue and Guinan, 1994). These fibers have given us an opportunity to examine the effects of efferent stimulation on afferent responses at audio frequencics.

Although we found that efferent stimulation excites vestibular afferents, our findings are somewhat different from those reported for stimuli at lower frequencies in different species (Goldberg and Fernández, 1980; Boyle and Highstein, 1990). We found efferent stimulation amplified (rather than reduced) responses to mechanical stimuli. Efferent activity induced no improvement in the ability of afferents to transduce stimuli linearly in both directions (i.e., produced no improvement in bidirectionality). We also present evidence for the existence of multiple driving mechanisms that can be differentially influenced by efferent stimulation. An important note: the purpose of this report is to document the existence of new phenomena and not to analyze them exhaustively.
A preliminary report of this work has been presented (McCue and Guinan, 1993).

\section{Materials and Methods}

Surgical preparation, anesthesia, sound stimulation, and neural recording were performed as described in the preceding article (McCue and Guinan, 1994), with the following modifications.

Surgical preparation. Middle ear muscle tendons were cut bilaterally. After a posterior craniectomy, both the lateral and medial parts of the cerebellum were aspirated to expose the dorsal surfaces of the temporal bone and brainstem. The roof of the internal auditory meatus was drilled away to reveal the junction of the inferior and superior vestibular nerves as described in McCue and Guinan (1994).

Sound stimulation. Acoustic stimuli consisted of $100 \mathrm{msec}$ tone bursts $\left(2.5 \mathrm{msec} \cos ^{2}\right.$-shaped rise-fall time) at a frequency of $800 \mathrm{~Hz}$, which is near the best frequency for acoustically responsive vestibular afferents (McCue, 1993).

Efferent stimulation. The cochlear and vestibular efferent axons travel together at the dorsal surface of the brainstem (Fig. 1). The efferent bundles were electrically stimulated using an eight-conductor linear electrode array $(0.5 \mathrm{~mm}$ separation between tips) oriented rostrocaudally at the midline of the dorsal brainstem as in Gifford and Guinan (1983). For vestibular efferent stimulation, we chose the electrode pair that maximized the inhibitory effects of cochlear efferent stimulation on the click-evoked compound action potential of the cochlear nerve as previously described (Gifford and Guinan, 1983).

Shock stimuli were bursts of $0.3 \mathrm{msec}$ rectangular voltage pulses filtered through a transformer to the remove the DC component. Our standard stimulus sequence had 64 shock bursts at $1.5 \mathrm{sec}$ intervals with each shock burst duration of $0.4 \mathrm{sec}$, at a shock rate of $200 / \mathrm{sec}$. Shock amplitude was fixed at $1 \mathrm{~dB}$ below the level that initiated a visible twitch of any muscle (typically 1-3 V).

Recording. Single units were recorded using 2 м KCl micropipettes inserted into the inferior vestibular nerve (Fig. 1) as described in McCue and Guinan (1994). Shock-evoked electrical artifact picked up by the recording microelectrode was minimized using a grounded aluminumfoil shield suspended between the stimulating and recording electrodes.

Event timing and analysis. Spikes, stimulus triggers, and the positive- 
A VESTIBULAR SYSTEM

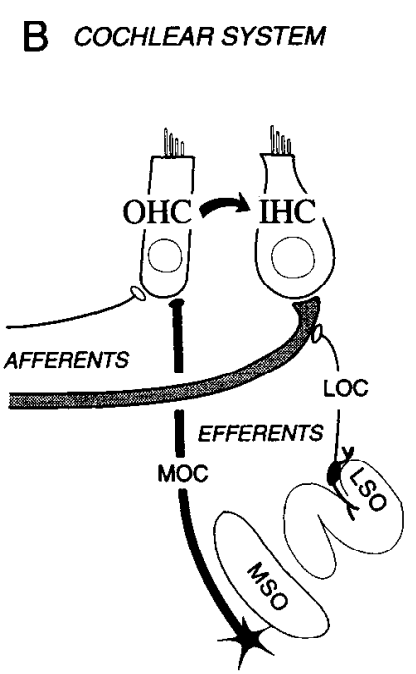

Figure 2. Schematic showing the relationships of hair cells and fibers in the vestibular $(A)$ and cochlear $(B)$ systems. Each system contains cylindrical cells (type II or $O H C s$ ) and flask-shaped cells (type I or $I H C s$ ), each of which has afferent innervation. Efferent fibers synapse on the cylindrical cells ( $V E-I I$ or $M O C$ efferents) or on the afferent dendrites under the flask-shaped cells ( $V E-I$ or $L O C$ efferents). $A$, Type I vestibular hair cells are innervated by myelinated afferent fibers that form a chalice around the cell and often branch to synapse on type II hair cells. Type II vestibular hair cells are innervated by small myelinated afferents with bouton endings. A single efferent neuron may produce VE-I and VE-II endings. $B$, Each IHC is innervated by many myelinated afferents, each with a small ending. OHCs are innervated by a few unmyelinated afferents. The efferent innervation to the two hair cell regions is mostly separate in the cochlea, with myelinated MOC efferents synapsing on OHCs and unmyelinated LOC efferents synapsing on radial afferent dendrites. MOC stimulation induces a change (probably mechanical) in OHCs that can affect IHCs ( $B$, curved arrow). The action of LOC neurons on cochlear afferents has not been demonstrated. $V E-I$, vestibular efferent ending on type I afferent dendrite; $V E-I I$, vestibular efferent ending on type II hair cell. VI, abducens nucleus; $M S O$, medial superior olive; $L S O$, lateral superior olive; $L O C$, lateral olivocochlear neurons; $M O C$, medial olivocochlear neurons. See text for literature citations.

going zero crossings of stimulus voltage waveforms were recorded with microsec accuracy by special-purpose hardware. Event times were used to calculate poststimulus time (PST) histograms (e.g., Figs. 3, 5), from which rate measurements were made (Fig. 6). Calculated rates were used to construct rate-level functions (Figs. 7,8).

To quantify the tendency of a unit to synchronize to individual phases of a tone cycle, we first computed a postzero crossing (PZC) histogram relating spike occurrences to the positive-going zero crossings of earphone voltage. From the PZC histogram, we computed a fast Fourier transform and from this obtained the synchronization index and the response phase. The synchronization index is the magnitude of the first (fundamental) Fourier component divided by the total number of spikes in the PZC histogram, and the response phase is the phase of the first Fourier component (Goldberg and Brown, 1969; Johnson, 1980; Gifford and Guinan, 1983). The synchronization index ranges from 0 (no synchronization) to 1 (all spikes in one bin).

Measurement protocol. All vestibular afferents with audible irregularity in rate (corresponding to a coefficient of variation $>0.15$ ) were tested for acoustic responses as described in McCue and Guinan (1994). Detection of an acoustically responsive unit initiated a standard measurement protocol. First, a tuning curve was taken as described by McCue (1993) followed by a $20 \mathrm{sec}$ measurement of background activity. Next, we obtained responses to shocks alone ( 64 shock bursts at $1.5 \mathrm{sec}$ intervals). Sound-alone sequences were then alternated with concurrent sound/shock sequences. Brief rest periods were inserted occasionally to permit any shock-evoked response to return to baseline. Typically, sound levels were tested in the following order: $110,100,90,80,105,95,85$ dB SPL. Shock amplitude remained fixed throughout. A complete data set (all sound levels tested) required a unit holding time longer than 15 $\min$.

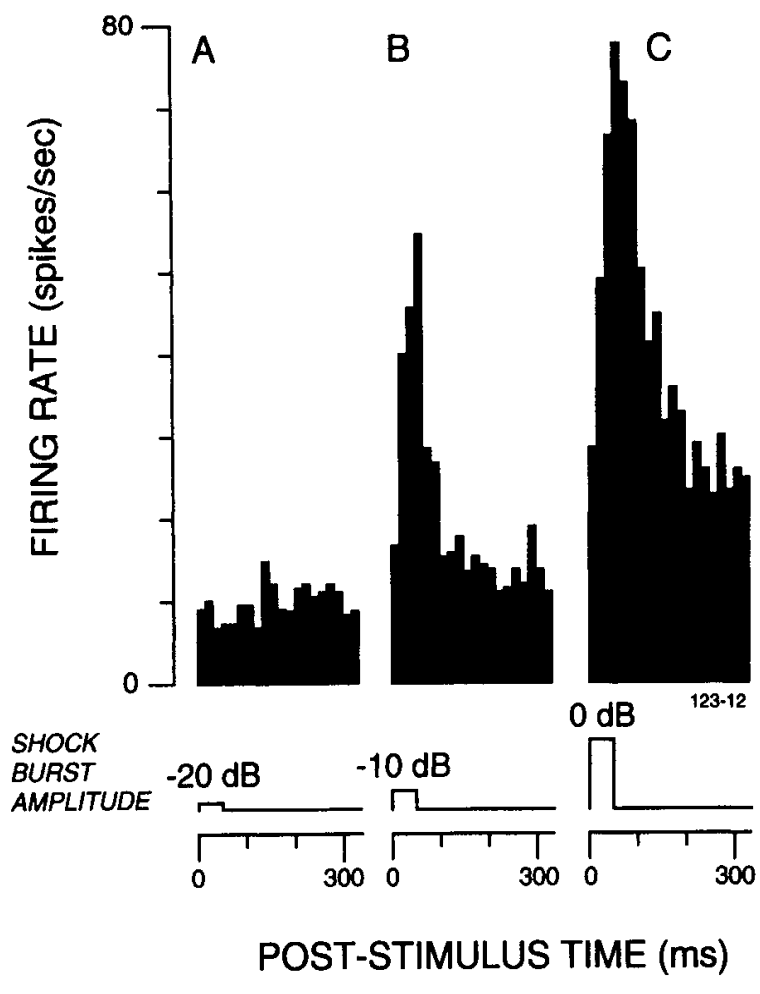

Figure 3. Influence of three levels of efferent shocks on the background activity of an acoustically responsive vestibular afferent. Poststimulus time histograms (top) show afferent discharge rates at three efferent shock levels (bottom traces). Stimuli were $50 \mathrm{msec}$ shock trains (shock rate, $200 / \mathrm{sec} ; 128$ bursts at $333 \mathrm{msec}$ intervals). Bins: $n=20$, width $=$ $16.5 \mathrm{msec}$. Data from cat 123 .

\section{Results}

We recorded background and sound-evoked responses from acoustically responsive irregularly discharging (ARID) vestibular afferents while stimulating vestibular efferent neurons with shocks applied at the dorsal surface of brainstem (Fig. 1). The influence of efferent stimulation on ARID vestibular afferents was examined in eight cats. In early experiments, many parameters were varied in an attempt to understand the basic phenomena. In the final experiment (cat 141), we standardized our stimulation and recording protocols and collected data from 15 afferent fibers in one ear to obtain adequate documentation of the phenomena. Data from these fibers are analyzed here and supplemented with corroborating data from earlier experiments.

\section{Influence of efferent shocks}

Efferent stimulation at shock rates of $200 / \mathrm{sec}$ caused incrcased firing rates in all vestibular afferents examined, both regular and irregular. No evidence for inhibition was found in ARID vestibular afferents or in our cursory examination of other nearby vestibular afferents. Excitatory effects were more prominent in irregularly discharging afferents than in regularly discharging afferents, and were similar in many respects to those previously observed in squirrel monkey vestibular afferents (Goldberg and Fernández, 1980). As shown in Figure 3, ARID vestibular afferents responded to brief bursts of efferent shocks with increased firing rates that depended on shock amplitude.

Efferent excitation consisted of two components with different time courses. A fast component was evident as the firing rate rose and fell with each shock burst, even for short shock bursts 


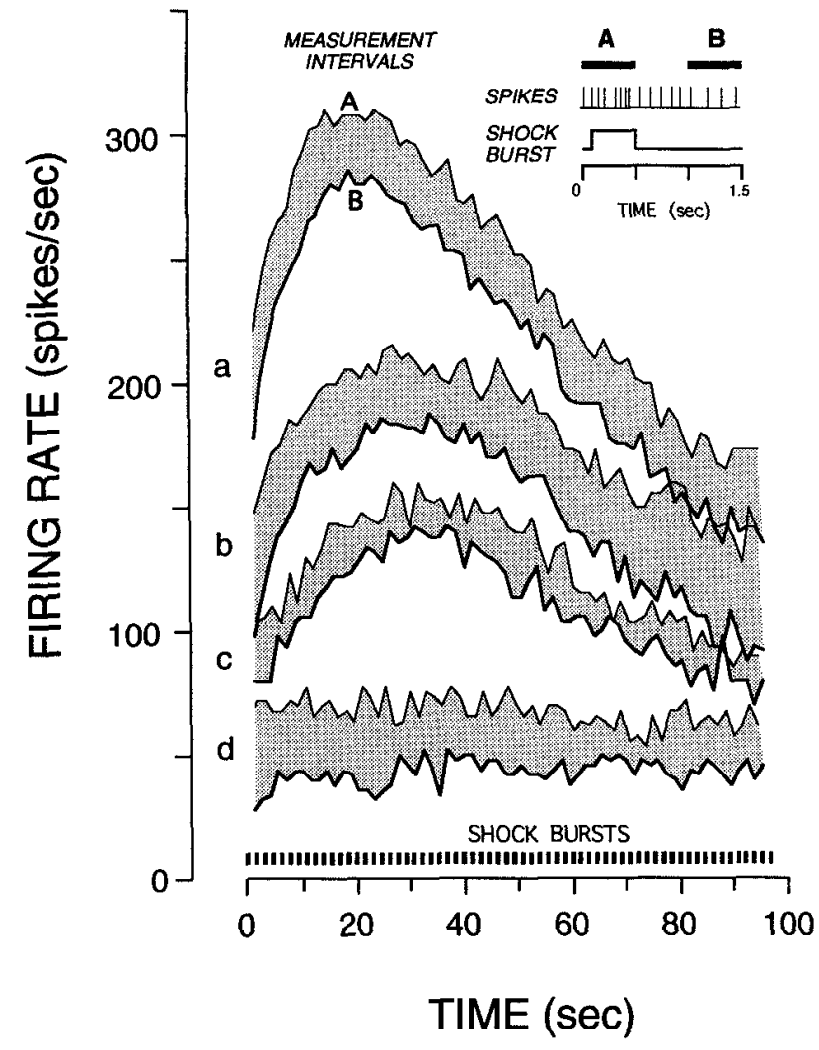

Figure 4. Slow- and fast-excitation components elicited by efferent stimulation in four acoustically responsive vestibular afferents $(a-d)$. Afferents were selected to show a range of evoked rates. Stimuli were repeated $0.4 \mathrm{sec}$ shock bursts ( 64 bursts at $1.5 \mathrm{sec}$ intervals with a shock rate of $200 / \mathrm{sec}$ ) as shown (bottom and inset). Thick lines show the slow $(20-40 \mathrm{sec})$ buildup and decay of the mean rate in measurement interval $\mathbf{B}$ (inset). Thin lines show the firing rate during measurement interval $A$ (inset). The fast component of each excitatory response (height of shaded area) usually varied less than the slow component (thick line).

(Fig. 3). A slower component was also evident as the background firing rate increased with each successive shock burst (over a $20-40 \mathrm{sec}$ period) and then decayed back to its baseline activity over a longer time period (Fig. 4). The slow buildup of background activity was evident in 12 of 13 afferents tested quantitatively. The fast response component amplitude remained relatively constant throughout the stimulus sequence, despite the sometimes dramatic rise and fall of the slow response component (Fig. 4).

\section{Influence of sound}

As reported in the preceding article (McCue and Guinan, 1994), low-frequency sound at levels $90 \mathrm{~dB}$ SPL or higher increased the discharge rate of ARID vestibular afferents (Fig. 5A). In addition, ARID vestibular afferents fired preferentially at a given phase of the tone cycle for sound levels higher than approximately $10 \mathrm{~dB}$ below their thresholds for rate increases.

\section{Influence of efferent shocks on acoustic responses}

Firing rate. Figure $5 B$ shows the influence of efferent stimulation on sound-evoked responses in an ARID vestibular afferent. Efferent shocks raised the background activity with a fast component (seen in each panel) and slow component (seen by comparing the background rates in Fig. $5 A, B$ ). As sound level was increased, sound-evoked responses made their first appearances at similar levels with and without efferent activation (Fig. $5 A, B$ ). At the highest sound levels, sound-evoked responses were superimposed on the crest of shock-evoked responses with the maximal firing rate clearly elevated over the sound-alone response (Fig. 5).

We quantified absolute and evoked rates as shown in Figure 6 , and plotted the results as functions of sound level ("rate-level functions") for each ARID vestibular afferent. Figure 7 shows rate-level functions from four afferents chosen to illustrate a range of evoked firing rates. Efferent stimulation elevated the rate-level functions for ARID afferents (Fig. $7 A-D$ ), but had little or no effect on the additional activity evoked by sound (Fig. $7 E-H$ ). In particular, efferent stimulation did not significantly shift the acoustic response thresholds (Fig. $7 E-H)$, despite its evoking impressive increases in background activity (Fig. $7 A-D$ ). Results from all ARID vestibular afferents obtained in one cat are summarized in Figure 8 . Figure $8 A$ shows the mean acoustic response and its elevation by efferent stimulation. Figure $8 B$ shows the relative lack of efferent influence on the mean afferent activity evoked specifically by sound.

Phase locking. In response to low-frequency tones, ARID vestibular afferents have a strong tendency to fire at a prefcrred phase of the stimulus cycle (i.e., to "synchronize" or "phase lock") (McCue and Guinan, 1994). Figure 9 shows postzerocrossing (PZC) histograms that relate the occurrences of spikes to the positive-going zero crossings of the earphone voltage waveform. The PZC histograms in Figure 9 were calculated for the afferent shown in Figure 5 using only the spikes that occurred during the tone bursts. At the lowest sound levels tested (80$85 \mathrm{~dB}$ SPL), the afferent in Figure 9 displays clear spike synchronization, although there is no sound-evoked change in mean rate (Fig. 5). At low sound levels, this afferent fired throughout the stimulus cycle (Fig. 9, $80 \mathrm{~dB}$ SPL), while at higher sound levels it synchronized so strongly that its instantaneous firing rate was close to zero for much of the stimulus cycle (Fig. 9, $110 \mathrm{~dB}$ SPL).

The influence of efferent stimulation on phase-locking of this ARID vestibular afferent is shown in Figure $9 B$. At $80 \mathrm{~dB}$ SPL, the firing rate increased with efferent stimulation but there was little change in the shape of the PZC histogram (Fig. 9, left). Efferent stimulation increased both the average firing rate and the fluctuations in firing rate amplitude within the stimulus cycle. Thus, the net result of efferent stimulation was an amplification of both DC and AC components of the response. At higher stimulus levels (Fig. 9, right), a similar amplification occurred. More spikes occurred at a particular phase of the stimulus cycle, but there was relatively little change in the sharpness of the peaks. For the afferent of Figure 9, the preferred response phase did not shift with efferent stimulation.

From data such as those shown in Figure 9, we measured synchronization index and response phase as functions of sound level in the presence and absence of efferent stimulation. Figure 10 shows these results for the same four afferents whose rate characteristics are shown in Figure 7. Efferent stimulation induced little or no shift in synchronization or phase (Fig. 10), except in one afferent that showed a consistent phase advance (Fig. 10F).

\section{Dual-phase responses ("peak splitting") induced by efferent stimulation}

As sound level was increased from 90 to $110 \mathrm{~dB}$ SPL, most 


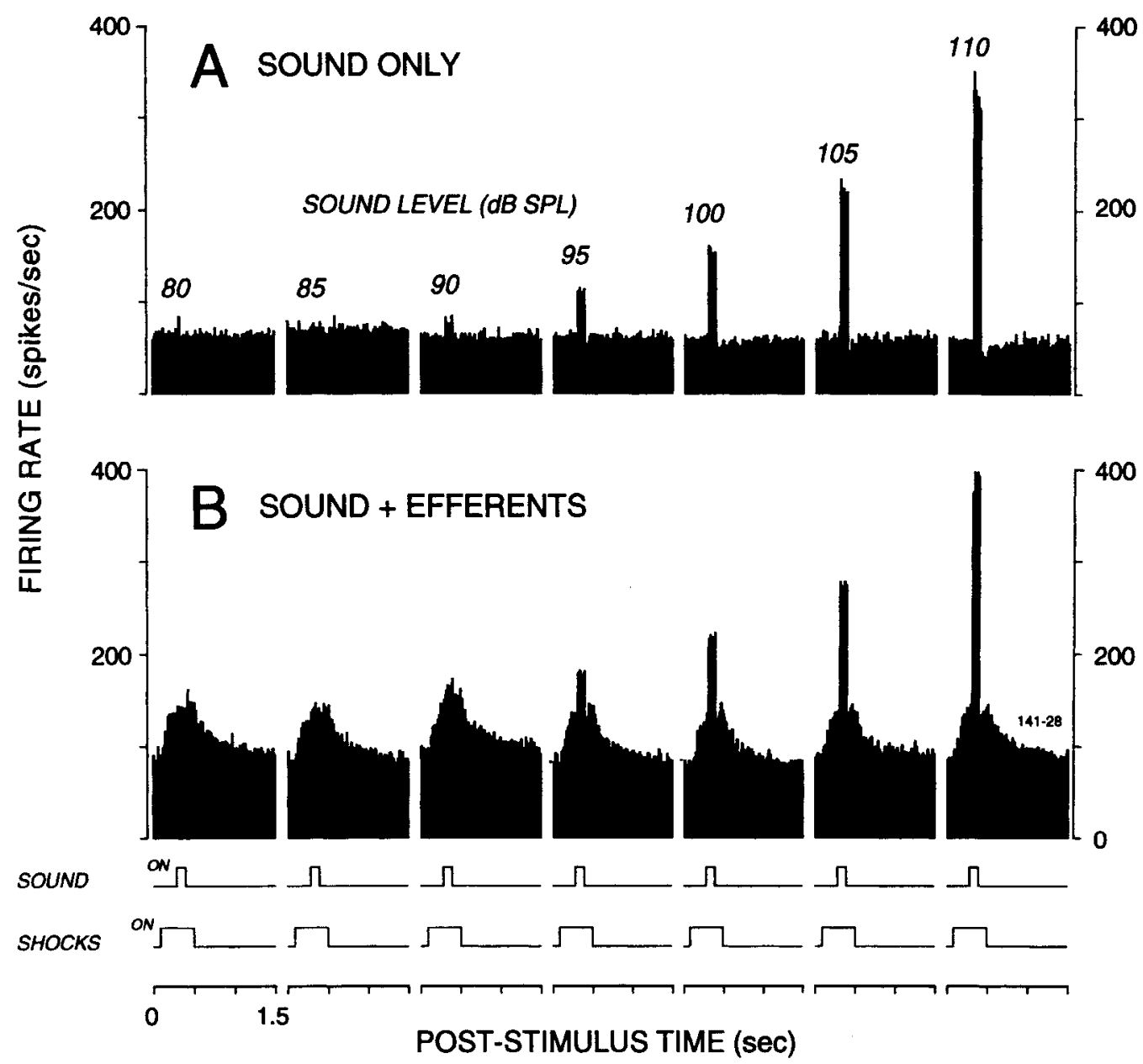

Figure 5. Influence of sound and efferent stimulation on the firing rate of an acoustically responsive vestibular afferent. $A$, PST histograms show the spike rate elicited by $800 \mathrm{~Hz}$ tone bursts of $0.1 \mathrm{sec}$ duration at seven sound levels. $B$, PST histograms show spike rate elicited during presentation of sound (as in $A$ ) with concurrent shock bursts to the efferent bundles. Stimulus presentation times are represented in the bottom traces. Each shock burst lasted $0.4 \mathrm{sec}$ (shock rate, $200 / \mathrm{sec} ; 64$ bursts at $1.5 \mathrm{sec}$ intervals). The difference in background activity between the histograms in $A$ and $B$ represents a time average of the slow excitatory response (see Fig. 4). Bins: $n=75$, width $=20.0$ msec.

ARID vestibular afferents underwent a greater than $30^{\circ}$ advance in their response phase (Fig. 10E-H) (McCue and Guinan, 1994). The origin of this phenomenon was clarified somewhat by examining the influence of efferent stimulation on the phase change.

During efferent stimulation at high sound levels, a sizable fraction of afferents $(6$ of 14) had responses with peaks at two phases (Fig. 11A). These phases can be compared to the preferred phases at 90 and $110 \mathrm{~dB}$ SPL in the absence of efferent stimulation, which we will refer to as phase 1 and phase 2, respectively (Fig. $11 B, D$ ). At $90 \mathrm{~dB}$ SPL, efferent stimulation augmented the existing response at phase 1 , for the afferent shown in Figure 11. At $110 \mathrm{~dB}$ SPL, the response was mainly at phase 2 in the absence of efferent stimulation (Fig. $11 B$ ), but the addition of efferent stimulation again caused an increase in responses at phase 1 , resulting in a response with peaks at two phases (Fig. 11A).

Figure 12 provides another example of an afferent in which efferent stimulation caused a double peak in the PZC histogram. Shown at top are the response phases for the first 500 spikes recorded during tone burst stimulation (Fig. 12A,C). The spike phases in Figure $12 C$ are representative of the whole spike cohort and show that spikes at the two component phases con-

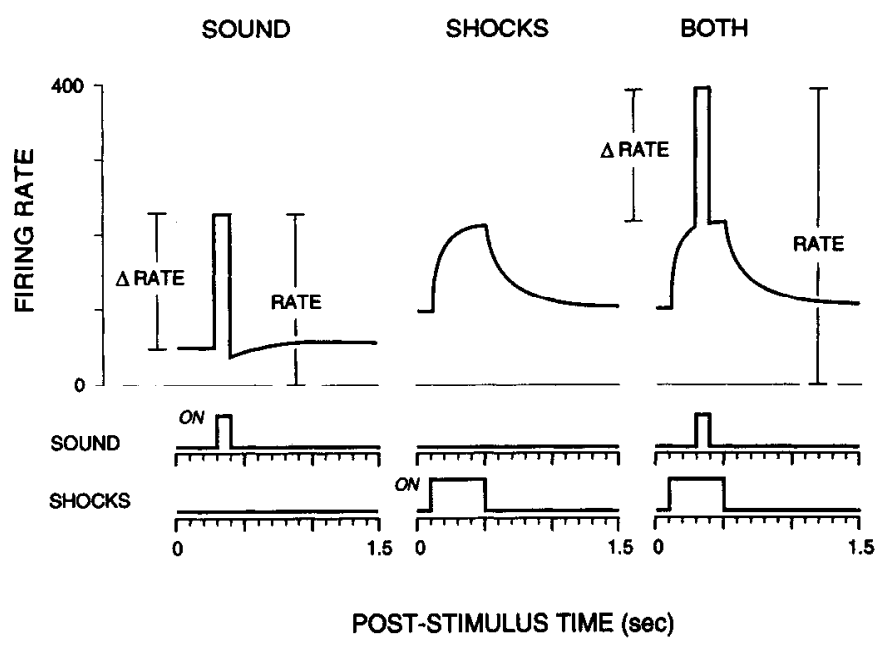

Figure 6. Quantification of evoked firing rates $(R A T E)$ and firing rate changes $(\triangle R A T E)$ from PST histograms. Calculations of RATE and $\triangle$ RATE were made from average measurements taken from each PST during three $50 \mathrm{msec}$ time periods beginning at $t=0,350$, and 450 msec. 

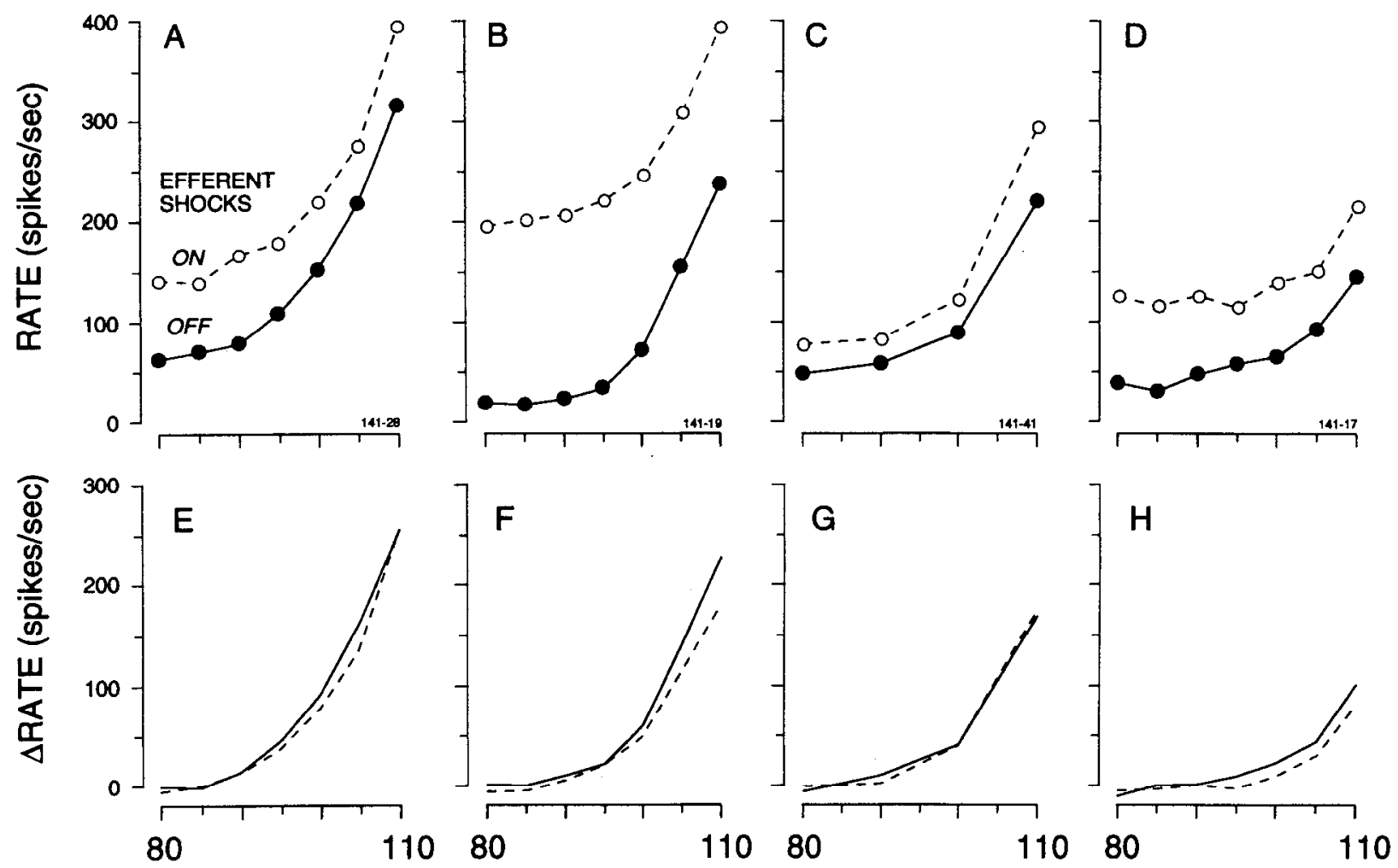

SOUND LEVEL (dB SPL)

Figure 7. Influence of efferent stimulation on the acoustically evoked firing rates of four vestibular afferents. Each column shows data from a different afferent. Measurements of absolute rate $(R A T E, A-D)$ and sound-evoked rate change ( $\triangle R A T E, E-H)$ were made from PST histograms taken at each sound level as shown in Figure 6. Solid lines show rates elicited by sound only. Dashed lines show rates elicited during concurrent delivery of sound and efferent shocks. Stimulus conditions were identical to Figure 5.

tributed more or less steadily to the flow of spikes-that one component did not dominate or drop out during data collection.

We found only one afferent (out of 14 afferents in the present sample plus 57 afferents sampled in McCue and Guinan, 1994) that clearly exhibited a split peak at $110 \mathrm{~dB}$ SPL in the absence of efferent stimulation. For this afferent, efferent stimulation completely reduced the response at phase 1 , producing one clear peak at phase 2 (i.e., the efferent effect was on the opposite peak from the effect shown in Fig. 11). Half of the afferents in our sample ( 7 of 14) had no split peaks with efferent stimulation, including the afferents whose data are shown in Figures 7 and 10.

\section{Discussion}

\section{Mechanism of efferent influence}

In the last few years, the anatomy of the neural elements in the mammalian vestibular end organs has been substantially clarified, and correlations with physiological responses have been made (Ross et al., 1986; Baird et al., 1988; Fernández et al., 1988, 1990; Goldberg et al., 1990a,b). The majority of mammalian vestibular afferents, both regularly and irregularly discharging, are dimorphic afferents (Fig. $2 A$, shaded afferent) that have calyceal endings around type I hair cells and variable numbers of branches to type II hair cells (Baird et al., 1988; Goldberg et al., 1990b). A minority of afferents (1-10\%) are pure calyx afferents that end only around type I hair cells and have irregular discharges (Baird et al., 1988; Goldberg et al., 1990b). The remaining vestibular afferents $(2-20 \%)$ are bouton afferents-small fibers that terminate solely on type II hair cells (Fig. $2 A$, unshaded afferent; Baird et al., 1988; Goldberg et al., 1990b). Vestibular efferent endings are primarily on type II hair cells (VE-II in Fig. 2) and on the afferent dendrites of type I hair cells (VE-I in Fig. 2) (Lindeman, 1973; Wersäll and Bagger-Sjoback, 1974; Fernández et al., 1988). Both of these efferent endings have ultrastructural characteristics of chemical synapses (Spoendlin, 1970).

A considerable body of data is consistent in indicating that efferent synapses on hair cells exert an inhibitory effect. In the lateral line organs (Flock and Russell, 1973a) and the turtle cochlea (Art et al., 1984), efferent synapses on hair cells cause hair cell hyperpolarization and result in the inhibition of afferent discharges. Indirect evidence indicates that outer hair cells in the mammalian cochlea and short hair cells in the chicken cochlea are also hyperpolarized by efferent synapses on hair cells (Fex, 1967; Fuchs and Murrow, 1991). It seems reasonable that the efferent synapses on type II vestibular hair cells are also inhibitory. This hypothesis is supported by the data from small bouton fibers that innervate only type II vestibular hair cells: (1) labeling and other experiments show that these make up only a small percentage of vestibular fibers (Baird et al., 1988; Goldberg et al., 1990b), and (2) efferent inhibition was observed in only a small percentage of vestibular afferents (Goldberg and Fernández, 1980).

There are few data that reveal the effect of efferent synapses 
on afferent dendrites. In the toadfish, efferent excitation produced monosynaptic excitatory postsynaptic potentials (EPSPs) in vestibular afferents (Highstein and Baker, 1985). In the squirrel monkey, efferent excitation increased the firing rate of most fibers (Goldberg and Fernández, 1980). Since most vestibular afferents have calyces that receive efferent synapses (Wersäll and Bagger-Sjoback, 1974; Fernández et al., 1988), an attractive hypothesis is that efferent synapses on afferent dendrites exert excitatory effects. Thus, the leading hypothesis is that vestibular efferents exert an inhibitory effect on hair cells and an excitatory effect on afferent dendrites (Goldberg and Fernández, 1980).

As noted earlier, most vestibular afferents are dimorphic (Fig. $2 A$, unshaded afferent) and would be expected to be influenced both by efferent synapses on afferent calyces and by efferent synapses on type II hair cells. This may correspond to the fact that most vestibular afferents show both an efferent-induced increase in background firing (presumably from the efferent synapses on calyces) and a decrease in the response to motion stimuli (presumably from the efferent synapses on type II hair cells) (Goldberg and Fernández, 1980; see also Highstein and Baker, 1985).

In summary, the available data are consistent with the hypothesis that efferent synapses on hair cells inhibit and efferent synapses on afferent fibers excite, but the data are not compelling. Our finding of an experimental paradigm showing only efferent excitation in a hair cell end organ provides a model system in which the origin of efferent excitation might be determined without the confounding effect of efferent inhibition also being present. It may be that efferent excitation alone is present because the acoustically responsive vestibular fibers and the associated hair cells receive only excitatory efferent synapses (e.g., if the afferents are pure calyx afferents). Another possibility is that efferent fibers producing excitatory synapses are separated in the brainstem from the efferent fibers that produce inhibitory synapses (see Tanaka et al., 1989) and that the selectivity to excitation we have found was produced by the site of our electrical stimulation. In either case, the system has allowed excitation to be studied without a confounding simultaneous presence of inhibition. As we will discuss later, our data are consistent with the efferent excitation being due only to synapses on afferent dendrites.

\section{Influences of efferent stimulation on the background firing rate}

Efferent shock bursts raised the background firing rates of acoustically responsive irregularly discharging (ARID) vestibular afferents in the cat (Figs. 3, 4). This excitatory effect had a fast component that rose and fell with efferent shock bursts over 100-200 msec (Figs. 3, 5) and a slow component that built up over $20-40 \mathrm{sec}$ and then decayed during repeated shock bursts. Both components are similar to the influences of efferent stimulation observed previously in irregular vestibular afferents in the squirrel monkey (Goldherg and Fernández, 1980).

The fast excitatory component has a time course consistent with a direct synaptic effect on the afferent dendrite (Goldberg and Fernández, 1980), but the mechanism of the slow component is less obvious. Possible mechanisms include slow EPSPs, buildup of extracellular $\mathrm{K}^{+}$, or long-lasting (seizure-like) discharges of efferent neurons (Goldberg and Fernández, 1980). Another possibility is that the two effects represent the action of two different neurotransmitters, for example acetylcholine and CGRP (Sewell and Starr, 1991).
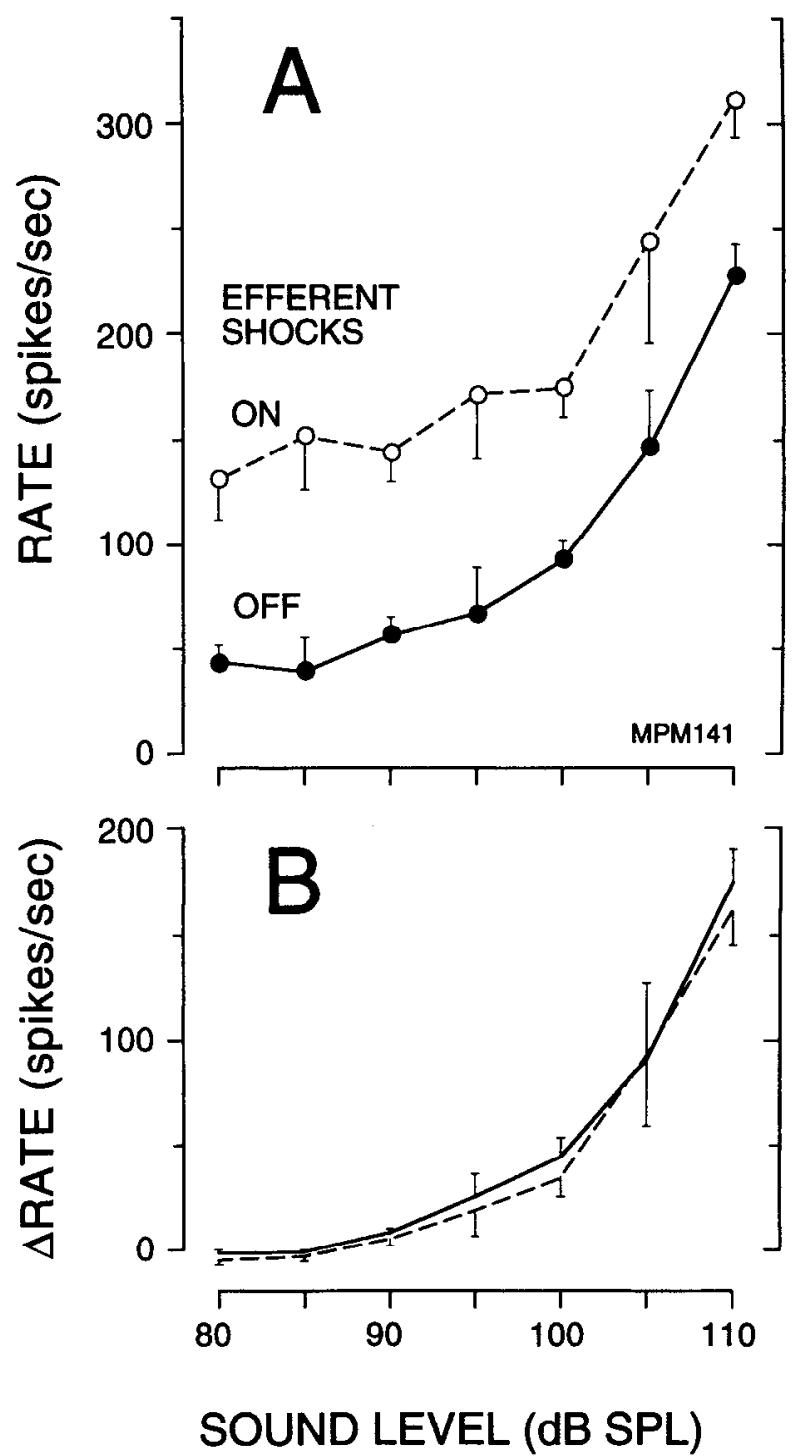

Figure 8. Mean influence of efferent stimulation on the sound-evoked firing rates from the acoustically responsive vestibular afferents of one ear. Absolute rate $(R A T E, A)$ and sound-evoked rate change ( $\triangle R A T E$, $B$ ) were obtained as shown in Figure 6 from PST histograms taken at each sound level. Solid lines show mean rates elicited by sound only. Dashed lines show mean rates elicited during concurrent delivery of sound and efferent shocks. Symbols in $A$ indicate which sound levels were tested. Error bars indicate SEM. More afferents were tested at "even" sound levels (ranging from $n=15$ at $110 \mathrm{~dB}$ SPL to $n=5$ at $80 \mathrm{~dB}$ SPL) than at "odd" sound levels $(n=3$ at each level). Stimulus conditions were identical to Figure 5.

Influences of efferent stimulation on acoustic responses: mean firing rate

Efferent stimulation raised the mean firing rates of acoustically responsive vestibular afferents without appreciably shifting their acoustic thresholds or the amplitude of their sound-evoked responses (Figs. 5, 7). The net effect was a vertical shift of the rate-level curve for each afferent, as schematized in Figure $13 \mathrm{~A}$. For afferents with low background activity, this shift could amount to a fourfold increase in background discharge rate (Fig. $7 B)$.

Efferent excitation of afferents with no change in the threshold or growth of the responses to sound is consistent with the efferent 


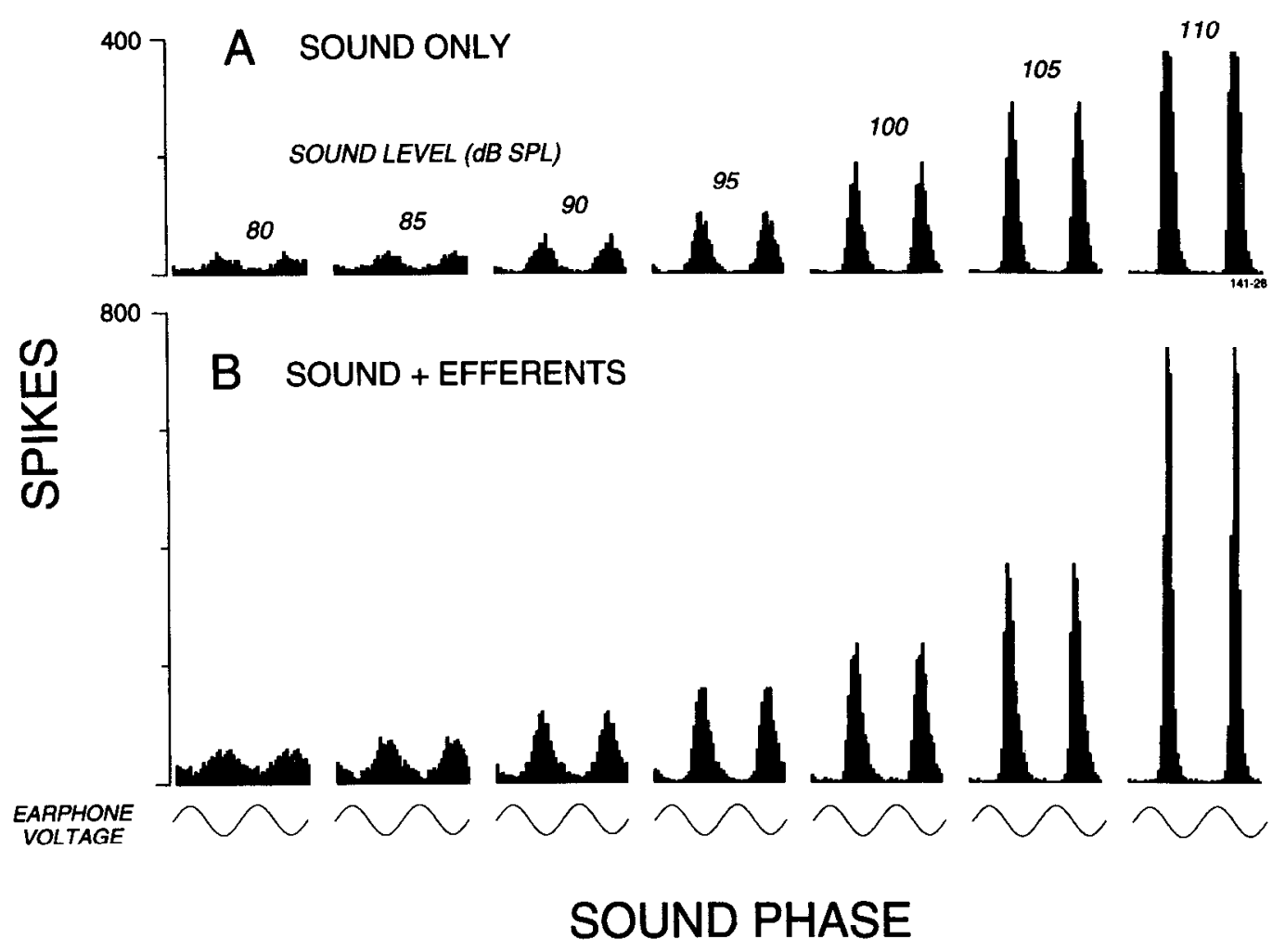

Figure 9. Influence of sound and efferent stimulation on the phase-locked responses of an acoustically responsive vestibular fiber. Postzerocrossing histograms show the phase-locked responses to $800 \mathrm{~Hz}$ tone bursts at increasing sound levels with efferent shocks OFF $(A)$ and ON $(B)$. Earphone voltage waveforms are shown at bottom. Fiber, stimulus conditions, and event data (only data from during the sound stimulation are used here) are the same as Figure 5. The ordinate is the total number of spikes that occurred in each bin during 5120 tone cycles. Shown are all of the spikes produced by the fiber (there has not been any removal of baseline spikes). The second response cycle is a duplicate of the first cycle and was added to facilitate seeing the overall response shapes. Bins: $n=50$, width $=50 \mu \mathrm{sec}$.

effect being due to efferent synapses on afferent endings (e.g., on calyces). In contrast, this pattern is not consistent with the excitation being produced by efferent synapses on hair cells. Since the sound-evoked excitation of ARID vestibular afferents is likely to be through normal activation of hair cells by their stereocilia (McCue and Guinan, 1994), an efferent effect produced by synapses on the hair cell would be expected to change the threshold and response growth with increases in sound. Thus, the lack of an efferent effect on the responses to sound supports the hypothesis that efferent synapses on hair cells proper are not involved in producing the efferent effects reported here.

\section{Influences of efferent stimulation on acoustic responses: phase locking and "gain"}

Efferent stimulation influenced the phase-locked responses of afferent fibers in a characteristic way. At the lowest sound levels (e.g., $80 \mathrm{~dB}$ SPL), afferents responded with a sinusoidal modulation of firing rate (Fig. 9) and the firing rate did not fall to zero during any phase of the stimulus cycle. Efferent stimulation increased both the average firing rate and the magnitude of the within-cycle fluctuations in firing rate (Figs. 9, 14A). At high sound levels (e.g., $100 \mathrm{~dB}$ SPL and above), the firing rate was driven to near zero during part of the sound cycle. Again, efferent stimulation increased both the average firing rate and the magnitude of the within-cycle fluctuations in firing rate. Furthermore, the acoustic stimulus continued to drive the afferent firing rate to zero over much of the sound cycle (Figs. 9, 14B). These observations indicate that both "spontaneous" afferent firings and efferent-induced afferent firing are modulated by the acoustic stimulus in the same way. This is confirmed by the lack of a substantial efferent-induced change in synchronization index (Fig. 10A-D) in fibers that are being substantially excited by efferents (Fig. 7).

Even though sound frequencies are orders of magnitude higher than the frequencies normally used in vestibular experiments, our results can be compared with motion results in terms of efferent-induced changes in the "AC gain" of vestibular afferents. Here, we use the term "AC gain" as normally defined in vestibular physiology (i.e., the firing rate change per degree of mechanical change for sinusoidal mechanical stimuli). With this definition, an efferent-induced increase in firing rate fluctuations indicates that efferents increased the "gain" because an increased number of spikes are evoked per degree change of the mechanical stimulus (note that efferents would not change the "gain" if "gain" were defined as the firing rate change per degree of mechanical change normalized by the average firing rate). This efferent-induced enhancement of "gain" (Figs. 9, 14A,B) contrasts sharply with the efferent-induced reduction of "gain" found in toadfish afferents (Highstein and Baker, 1985; Boyle and Highstein, 1990; see Fig. 14C,D) and in the majority of squirrel monkey afferents (Goldberg and Fernández, 1980). The few vestibular afferents in the squirrel monkey that exhibited "gain" enhancement were afferents with low background firing rates (Goldberg and Fernández, 1980). 

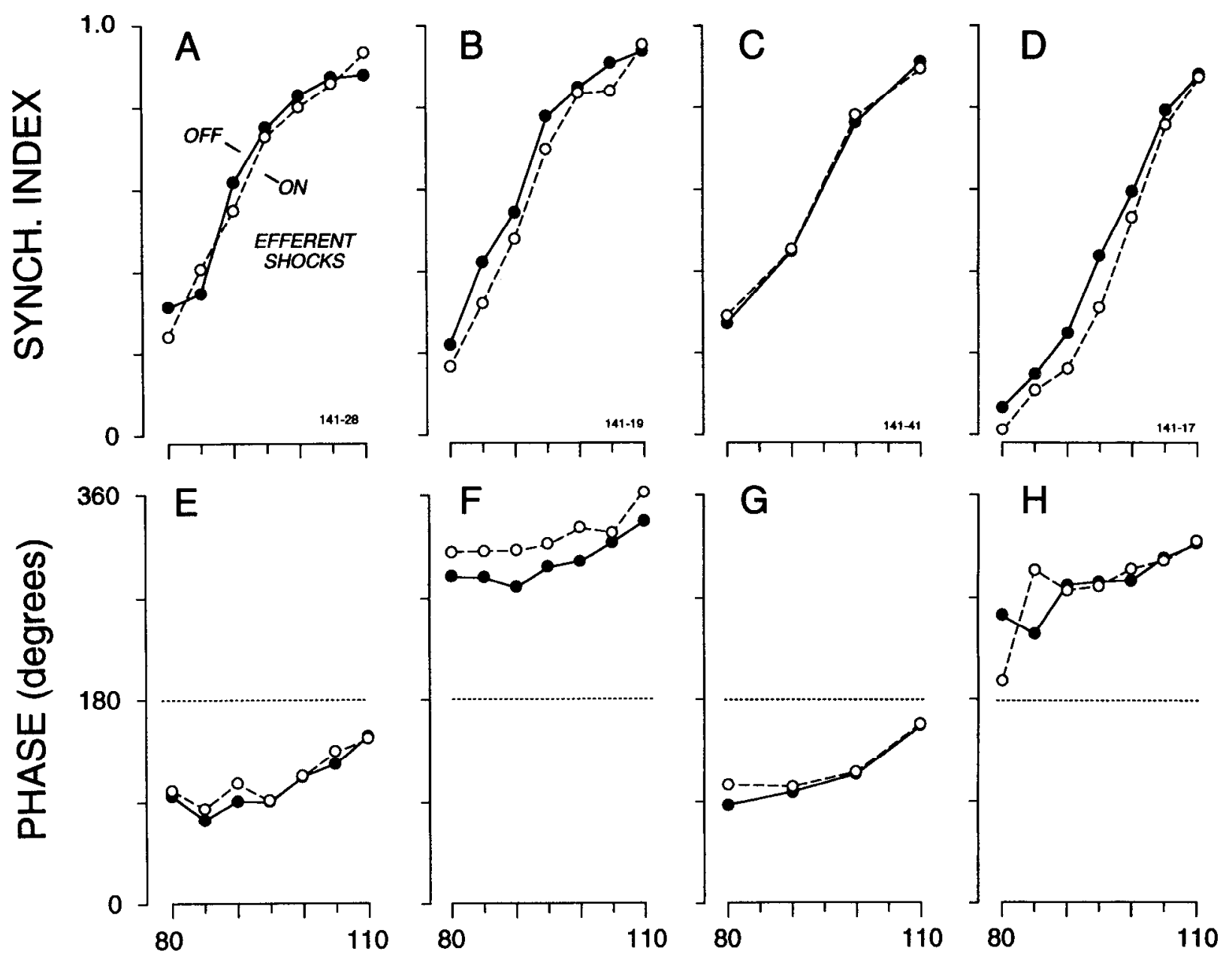

\section{SOUND LEVEL (dB SPL)}

Figure 10. Influence of efferent stimulation on the phase-locked responses of four acoustically responsive vestibular afferents. Each column shows data from a different afferent. Measurements of synchronization index $(A-D)$ and phase $(E-H)$ were made from Fourier transforms of PZC histograms (e.g., Fig. 9). Values were obtained from responses to sounds with efferent shocks OFF (solid lines) and ON (dashed lines). Symbols indicate which sound levels were tested. Afferents, stimulus conditions, and data are identical to those in Figure 7 . The dotted line at $180^{\circ}$ in $E-H$ emphasizes our finding (see preceding article, McCue and Guinan, 1994) that ARID afferents fall into two classes with preferred response phases approximately $180^{\circ}$ apart ( $E$ and $G$, PUSH afferents; $F$ and $H$, PULL afferents). Note that most ARID afferents exhibit a phase shift of about $30^{\circ}$ between 90 and $110 \mathrm{~dB}$ SPL $(E-H)$.

We did not see an example (such as Fig. 14D) in which efferent excitation biased the afferent responses to higher firing rates and thereby improved the bidirectionality (signaling of opposite mechanical phases) of responses. Improvements in response bidirectionality have been seen in other species and have been advanced as a rationale for efferent-induced increases in afferent firing rate (Goldberg and Fernández, 1980; Boyle and Highstein, 1990).

The mechanism for the efferent enhancement of vestibular afferent "gain" is unclear. One possible mechanism is that efferent synapses on calyces act on afferent membrane channels (perhaps through a second messenger) to increase the overall resistance of the afferent dendrite. If afferent background activity is generated by random releases of variable amounts of hair cell transmitter, and the amplitudes of the resultant potentials vary with the resistance of the afferent dendrite (like the miniature endplate potentials found in muscles by Katz and Thesleff, 1957), then an efferent-induced increase in the afferent dendrite's resistance would amplify both spontaneous and evoked afferent activity with little change in the tendency of discharges to synchronize (i.e., it would produce effects like those in Figs. 9, 10).

\section{Dual-phase responses}

A number of the phenomena reported here are reminiscent of similar phenomena seen in cochlear-nerve fibers (Gifford and Guinan, 1987). These include dual-phase responses at high sound levels, changes in phase with sound level, and preferential effects on one phase of a dual-phase response (Figs. 10-12). These phenomena suggest that ARID afferents are driven by two excitatory mechanisms that have different phases and are affected differently by efferent stimulation. A shift from a longer-latency excitatory mechanism that is dominant at low sound levels to a shorter-latency excitatory mechanism that is dominant at high sound levels would explain the $30^{\circ}$ advance in phase that is 


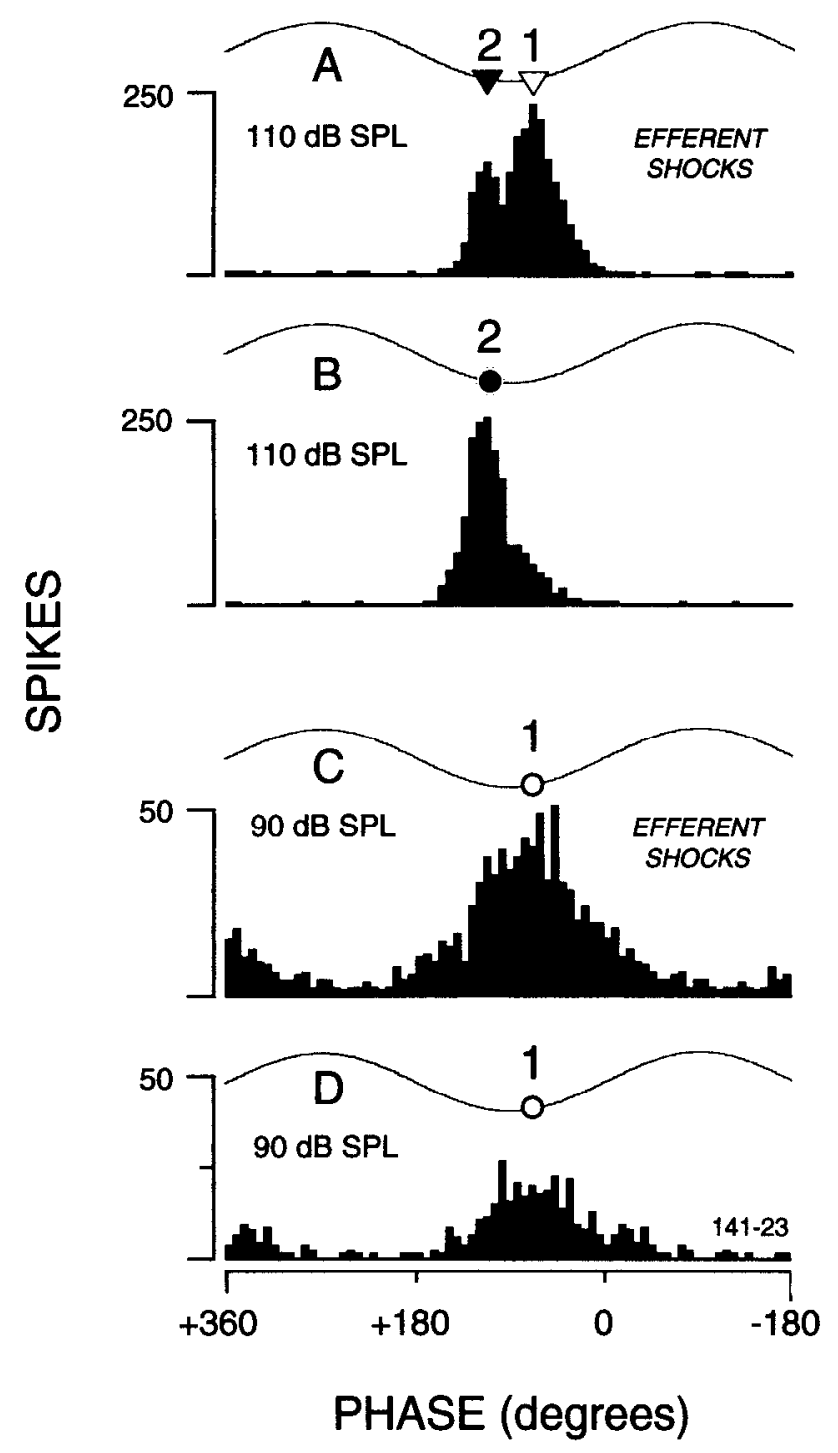

Figure 11. Efferent-induced dual-phase responses. $A-D, \mathrm{PZC}$ histograms obtained at $110 \mathrm{~dB}$ SPL with efferent stimulation ON $(A)$ and OFF $(B)$ and at $90 \mathrm{~dB}$ SPL with efferent stimulation ON $(C)$ and OFF (D). Circles indicate phases calculated from Fourier transforms of the PZC histograms. Triangles indicate the two local maxima of the histogram in $A . B$ and $D$ show the $\geq 30^{\circ}$ phase advance (from phase $I$ to phase 2), which usually occurs in ARID afferents between 90 and 110 dB SPL (see Fig. $10 E-H$ ). At 90 dB SPL, efferent stimulation augmented the response at phase $I(C$ and $D$, open circles). At $110 \mathrm{~dB}$ SPL, the response without efferent stimulation occurred at phase $2(B)$, and efferent stimulation caused the reappearance of a response component at phase $l(A)$. Stimulus conditions identical to Figure 5 . PZC histograms as in Figure 9 . The ordinate is the total number of spikes that occurred in each bin during 5120 tone cycles.

typically seen in ARID vestibular afferents (Fig. 7; McCue and Guinan, 1994).

Three hypotheses can be considered for the origin of the two factors. One is that the dual-phase responses reflect peaks in a distorted mechanical drive to the hair cells (see Mountain and Cody, 1989). With this hypothesis, efferents affect the response by changing the mechanical response of the epithelium (see Denk and Webb, 1992), presumably through efferent synapses on type II hair cells, in much the same way as the putative effect of outer hair cells on the cochlear epithelium. Since responses at both phases are present in short succession (Fig. 12C), effer-

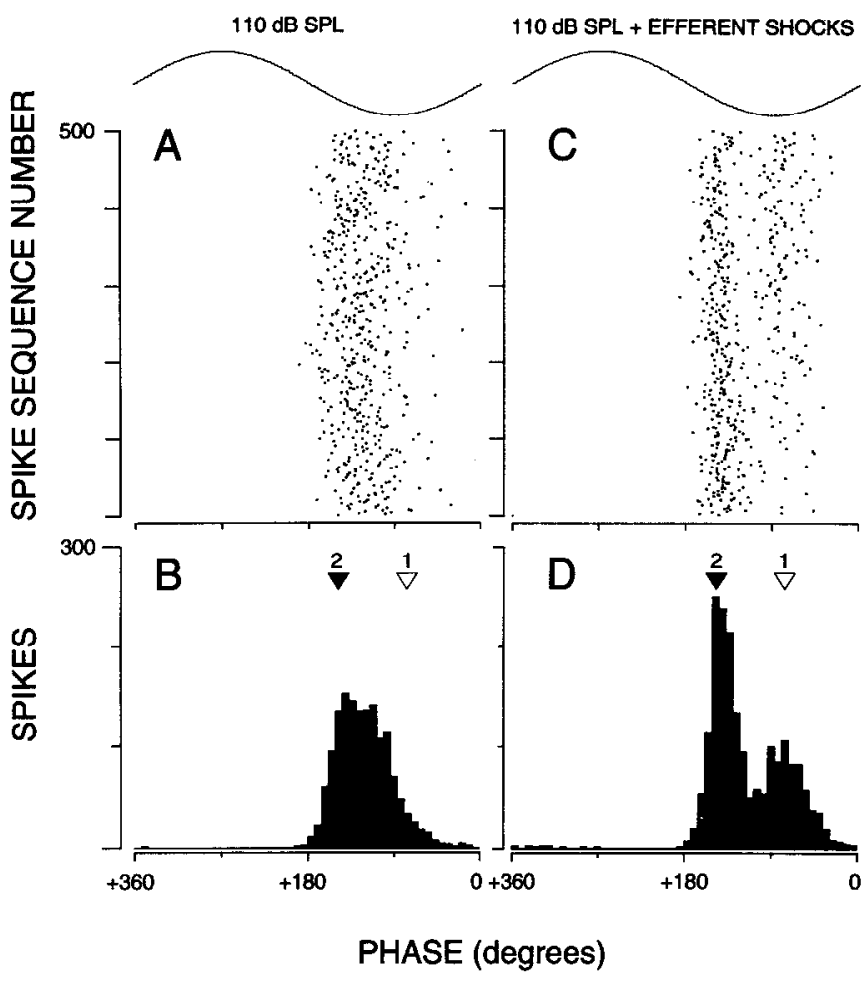

Figure 12. The randomness of dual-phase acoustic responses during efferent stimulation. $A$ and $C$, Response phases of the first 500 spikes that occurred during the sound stimulus (110 dB SPL) with efferent stimulation OFF $(A)$ and $\mathrm{ON}(C) . B$ and $D$, PZC histograms of all spikes that occurred during the sound stimulus interval with efferent shocks $\mathrm{OFF}(B)$ and $\mathrm{ON}(D)$. Triangles in $B$ and $D$ indicate the two local maxima of the histogram in $D$. The ordinate in $A$ and $C$ is the sequence number of the spikes in order of occurrence. The ordinate in $B$ and $D$ is the total number of spikes that occurred in each bin during 5120 tone cycles. $C$ shows that there are no long runs of spikes at phase 1 alternated with long runs of spikes at phase 2 .
A VESTIBULAR SYSTEM

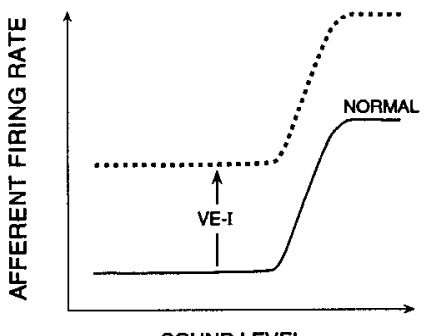

SOUND LEVEL

\section{B COCHLEAR SYSTEM}

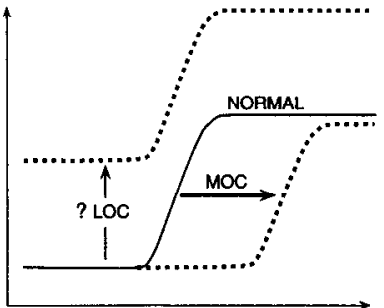

SOUND LEVEL
Figure 13. Schematic showing possible analogies between the interactions of efferent and afferent fibers in the vestibular $(A)$ and cochlear $(B)$ systems. See Figure 2 for anatomical arrangement and abbreviations. Rate-level functions are shown for spikes elicited with efferent stimulation OFF (solid lines) and ON (dashed lines). A, Stimulation of efferent endings on afferent dendrites $(V E-I)$ increases the firing rate of vestibular afferents without shifting their acoustic thresholds (see Figs. 7, 8). $B$, Stimulation of MOC neurons shifts the acoustic threshold of cochlear afferents by producing a change (probably mechanical) in OHCs that affects IHCs (Fig. 2B). The action of LOC neurons on cochlear afferents remains unknown, but the analogous neural connections (Fig. 2) suggest that LOC endings may work like VE-I endings, raising afferent firing rate without affecting rate threshold $(B)$. 
CAT

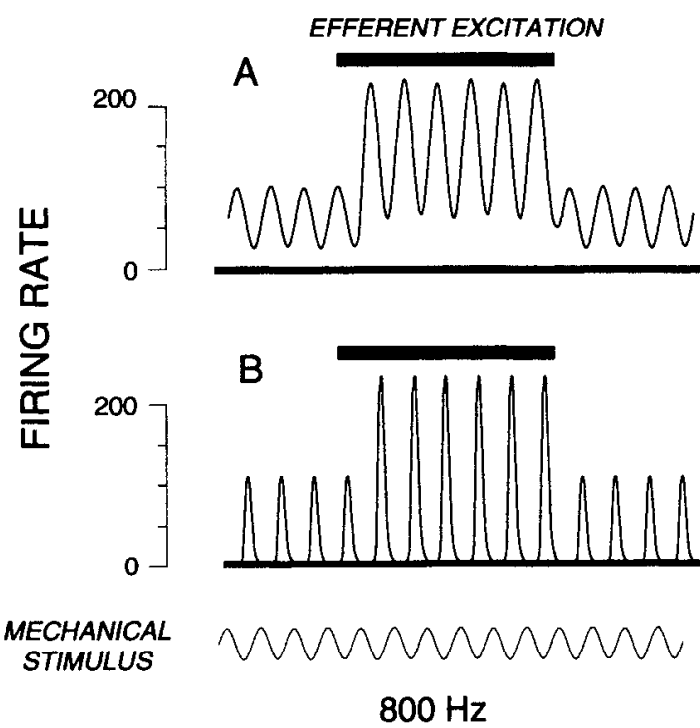

TOADFISH

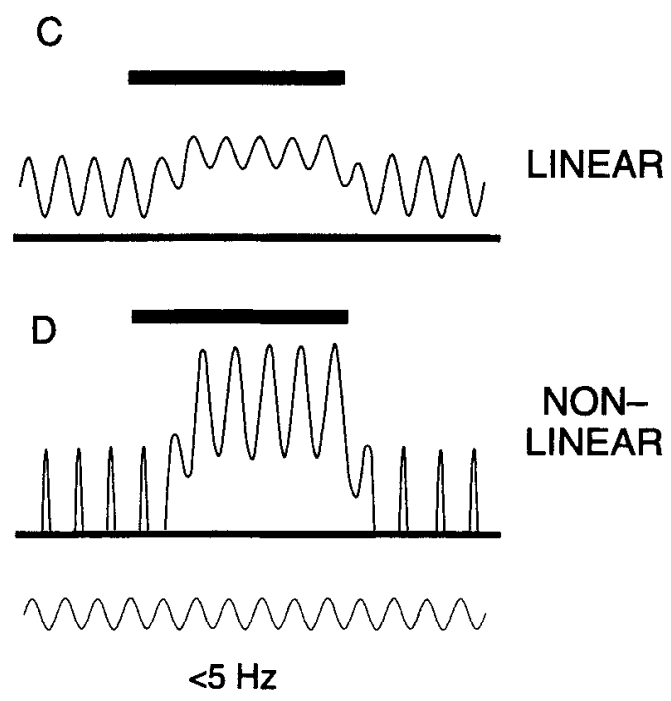

Figure 14. Schematic showing the different efferent influences on mechanically evoked responses found in vestibular afferents in the cat $(A, B)$ and toadfish $(C-D)$. $A$ and $C$, Transduction of a mechanical stimulus in which the firing rate never falls to zero (linear transduction). $B$ and $D$, Transduction in which the firing rate falls to zero (nonlinear transduction). $A$ and $B$, In cat afferents stimulated by $800 \mathrm{~Hz}$ tones, efferent stimulation increases the amplitude of both the $\mathrm{AC}$ and $\mathrm{DC}$ response components in both the linear and nonlinear regions (Fig. 9). $C$ and $D$, In toadfish afferents stimulated at low frequencies $(<50 \mathrm{~Hz})$, efferent stimulation elevated the DC component while reducing the AC component, making the transduction process bidirectional for afferents that operate in the nonlinear region $(D)$ ( $C$ and $D$ according to Boyle and Highstein, 1990).

ents must change an existing distortion and not just the phase of a simple mechanical response.

A second hypothesis is that afferents with dual-phase responses are dimorphic afferents and that each hair cell type contributes to one phase of the response. Presumably, efferent synapses on type II hair cells would inhibit type II contributions, while efferent endings on calyces would enhance type I contributions. To fit with the efferent enhancement of the longerlatency component (Fig. 11), the type I hair cells would have the longer-latency response, even though the calyx ending, with its thick, short connection to the afferent fiber, might be expected to produce the shortest-latency response.

A final hypothesis is that ARID afferents are calyx afferents that are coupled to type I hair cells through both chemical synapses and electrically conductive junctions, as has been suggested by the presence of certain membrane specializations (Spoendlin, 1966). A sound-level-dependent transition from slow chemical transmission to fast electrical transmission would advance the response phase, and could help explain the extremely short latencies ( $\leq 0.7 \mathrm{msec}$ ) exhibited by ARID vestibular afferents to intense acoustic clicks (McCue and Guinan, 1994). An efferent-induced increase in the resistance of the afferent terminal would increase the potency of chemical transmission and, depending on which membranes were affected, might also decrease electrical transmission. Thus, the hypothesis that efferents increase the afferent fiber membrane resistance is consistent with almost all of the phenomena we have seen.

\section{Comparison with efferent influences on cochlear afferents}

The influence of efferent stimulation on acoustic responses has been previously studied in cat cochlear nerve fibers (Fex, 1967; Wiederhold and Kiang, 1970; Guinan and Gifford, 1988), but this is the first such study of acoustic responses of vestibular nerve fibers. As we demonstrated in the preceding article (McCue and Guinan, 1994), the acoustically responsive vestibular afferents reported here likely originate in the saccule, the sensory organ in the inferior part of the labyrinth that is thought to have given rise to the cochlear duct during vertebrate evolution (Wever, 1974). The data presented here thus provide an opportunity to compare efferent influences on two mammalian sensory systems that have similarities in anatomy, physiology, and evolutionary origin.

As shown in Figure $2 B$, cochlear hair cells are similar to vestibular hair cells in that they are of two morphological types: flask-shaped inner hair cells (IHCs) and cylindrical outer hair cells (OHCs). Efferent endings are also arranged similarly, bcing found on OHCs (Kimura and Wersäll, 1962; Spoendlin and Gacek, 1963) and on the afferent dendrites under IHCs (Smith, 1961; Smith and Rasmussen, 1963). Cochlear efferent neurons are divided into two classes based on their peripheral projections and central origins (Warr and Guinan, 1979): medial olivocochlear (MOC) efferents end on OHCs and have cell bodies near the medial superior olive; lateral olivocochlear (LOC) neurons end on afferent dendrites under IHCs and have cell bodies near the lateral superior olive (Guinan et al., 1983).

Electrical stimulation of MOC neurons most likely hyperpolarizes (Fex, 1967) and induces a mechanical change (Brownell et al., 1985) in OHCs, which in some way decreases the acoustic responses of IHCs (Brown et al., 1983). The principal effect is to raise the acoustic threshold of $\mathrm{IHC}$ afferents and to shift their rate-level functions to higher levels (Fig. 13B) (Wiederhold and Kiang, 1970; Guinan and Gifford, 1988).

LOC neurons are the largest group of cochlear efferents (Warr, 1975; Warr and Guinan, 1979; Warr et al., 1986), yet their effects on cochlear afferents remain unknown, in part because LOC axons are unmyelinated and thus are not excited by standard efferent shock stimuli (Guinan et al., 1983; Gifford and Guinan, 1987). Anatomical similarities in the arrangement of neural 
elements in vestibular end organs (Fig. $2 A$ ) and the cochlea (Fig. $2 B$ ) suggest that the effect of LOC neurons may parallel the effect of the vestibular efferents studied here (Figs. $13 B, 14 A, B$ ). The analogy is attractive because of the likely homologous relationship of the systems and our conclusion that the efferent excitation of ARID afferents is most likely due to efferent synapses on afferent dendrites. In cochleas that were chronically deefferented, Liberman (1990) found a small decrease in the spontaneous rates of cochlear afferent fibers, an effect that would be consistent with LOC excitation.

Consequences and predictions. The data presented here may be useful in attempts to understand the LOC system. With the proposed analogy, LOC stimulation would elevate the background firing rate of cochlear afferents but have little effect on their rate thresholds or mean sound-evoked firing rates in response to tones (see Fig. 7). The net effect would be an LOCinduced vertical shift in the afferent ratc-level function that would "complement" the horizontal shift created by MOC activation (Fig. 13B). Also, LOC stimulation would increase the within-cycle $\mathrm{AC}$ modulation of afferent responses to tones, but without increasing the response synchronization index (Fig. $14 A, B)$. Predicting LOC effects on the responses to clicks is less clear, because we have not studied efferent effects on the click responses of ARID vestibular afferents. Although tone-evoked rate increases would be unchanged, the click-evoked compound action potential of the cochlear nerve $\left(\mathrm{N}_{1}\right)$ might increase under LOC activation owing to an enhanced, synchronized response to sounds. This might explain increases in the $\mathrm{N}_{1}$ amplitude elicited by opioid drugs, which are thought to mimic LOC effects (Sahley et al., 1991).

\section{References}

Art J, Fettiplace R, Fuchs PA (1984) Synaptic hyperpolarization and inhibition of cochlear hair cells. J Physiol (Lond) 356:525-550.

Baird RA, Desmadryl G, Fernández C, Goldberg JM (1988) The vestibular nerve of the chinchilla. II. Relation between afferent response properties and peripheral innervation patterns in the semicircular canals. J Neurophysiol 60:182-203.

Boyle R, Highstein SM (1990) Efferent vestibular system in the toadfish: action upon horizontal semicircular canal afferents. J Neurosci $10: 1570-1582$.

Brown MC, Nuttall AL, Masta RI (1983) Intracellular recordings from cochlear inner hair cells: effects of stimulation of the crossed olivocochlear efferents. Science 222:69-72.

Brownell WE, Bader CR, Bertrand D, de Ribaupierre Y (1985) Evoked mechanical response of isolated cochlear outer hair cells. Science 277: 194-196.

Denk W, Webb WW (1992) Forward and reverse transduction at the limit of sensitivity studied by correlating electrical and mechanical fluctuations in frog saccular hair cells. Hear Res 60:89-102.

Dieringer N, Blanks RHI, Precht W (1977) Cat efferent vestibular system: weak suppression of primary afferent activity. Neurosci Lett 5:285-290.

Fernández C, Baird RA, Goldberg JM (1988) The vestibular nerve of the chinchilla. I. Peripheral innervation patterns in the horizontal and superior semicircular canals. J Neurophysiol 60:167-181.

Fernández C, Goldberg JM, Baird RA (1990) The vestibular nerve of the chinchilla. III. Peripheral innervation patterns in the utricular macula. J Neurophysiol 63:767-780.

Fex J (1967) Efferent inhibition in the cochlea related to hair-cell dc activity: study of postsynaptic activity of the crossed olivo-cochlear fibers in the cat. J Acoust Soc Am 41:666-675.

Flock $\AA$, Russell IJ (1973a) The post-synaptic action of efferent fibres in the lateral line organ of the burbot Lota lota. J Physiol (Lond) 235: 591-605.
Flock $\AA$, Russell IJ (1973b) Inhibition by efferent nerve fibers: action on hair cells and afferent synaptic transmission in the lateral line canal organ of the burbot Lota lota. J Physiol (Lond) 257:45-62.

Fuchs PA, Murrow BW (1991) Inhibition of cochlear hair cells by acetylcholine. J Gen Physiol 98:28-29.

Galambos R (1956) Suppression of auditory activity by stimulation of efferent fibers to the cochlea. J Neurophysiol 19:424-437.

Gifford ML, Guinan JJ Jr (1983) Effects of crossed-olivocochlearbundle stimulation on cat auditory nerve fiber responses to tones. $J$ Acoust Soc Am 74:115-123.

Gifford ML, Guinan JJ Jr (1987) Effects of electrical stimulation of medial olivocochlear neurons on ipsilateral and contralateral cochlear responses. Hear Res 29:179-194.

Goldberg J, Brown PB (1969) Response of binaural neurons of dog superior olivary complex to dichotic tonal stimuli: some physiological mechanisms of sound localization. J Neurophysiol 32:613-636.

Goldberg JM, Fernández C (1980) Efferent vestibular system in the squirrel monkey: anatomical location and influence on afferent activity. J Neurophysiol 43:986-1025.

Goldberg JM, Desmadryl G, Baird RA, Fernández C (1990a) The vestibular nerve of the chinchilla. IV. Discharge properties of utricular afferents. J Neurophysiol 63:781-790.

Goldberg JM, Desmadryl G, Baird RA, Fernández C (1990b) The vestibular nerve of the chinchilla. V. Relation between afferent discharge properties and peripheral innervation patterns in the utricular macula. J Neurophysiol 63:791-804.

Guinan JJ Jr, Gifford ML (1988) Effects of electrical stimulation of efferent olivocochlear neurons on cat auditory-nerve fibers. I. Ratelevel functions. Hear Res 33:97-114.

Guinan JJ Jr, Warr WB, Norris BE (1983) Differential olivocochlear projections from lateral versus medial zones of the superior olivary complex. J Comp Neurol 221:358-370.

Highstein SM, Baker R (1985) Action of the efferent vestibular system on primary afferents in the toadfish, Opsanus tau. J Neurophysiol 54: 370-384.

Katz B, Thesleff S (1957) On the factors which determine the amplitude of the miniature end-plate potential. J Physiol (Lond) 137:267278.

Kimura RS, Wersäll J (1962) Termination of the olivocochlear bundle in relation to the outer hair cells of the organ of Corti in guinea pig. Acta Otolaryngol (Stockh) 55:11-32.

Klinke R, Galley N (1974) Efferent innervation of vestibular and auditory receptors. Physiol Rev 54:316-357.

Liberman MC (1990) Effects of chronic cochlear de-efferentation on auditory-nerve response. Hear Res 49:209-224.

Lindeman HH (1973) Anatomy of the otolith organs. Adv Otorhinolaryngol 20:405-433.

McCue MP (1993) Acoustic responses from primary vestibular neurons. $\mathrm{ScD}$ thesis, Massachusetts Institute of Technology.

McCue MP, Guinan JJ Jr (1993) Acoustic responses from primary afferent neurons of the mammalian sacculus. Assoc Res Otolaryngol Abstr 16:33.

McCue MP, Guinan JJ Jr (1994) Acoustically responsive fibers in the vestibular nerve of the cat. J Neurosci 14:6058-6070.

Mountain DC, Cody AR (1989) Mechanical coupling between inner and outer hair cells in the mammalian cochlea. In: Cochlear mechanisms. Structurc, function and models (Wilson JP, Kemp DT, eds), pp 153-160. New York: Plenum.

Ross MD, Rogers CM, Donovan KM (1986) Innervation patterns in rat saccular macula. Acta Otolaryngol (Stockh) 102:75-86.

Sahley TL, Kalish RB, Musiek FE, Hoffman DW (1991) Effect of opioid drugs on auditory evoked potentials suggest a role of lateral olivocochlear dynorphins in auditory function. Hear Res 55:133-142.

Sewell WF, Starr PA (1991) Effects of calcitonin gene-related peptide and efferent nerve stimulation on afferent transmission in the lateral line organ. J Neurophysiol 65:1158-1169.

Smith CA (1961) Innervation patterns of the cochlea. The internal hair cell. Ann Otol Rhinol Laryngol 70:504-527.

Smith CA, Rasmussen GL (1963) Recent observations on the olivocochlear bundle. Ann Otol Rhinol Laryngol 72:489-497.

Spoendlin II (1966) Some morphofunctional and pathological aspects of the vestibular sensory epithelia. In: Second symposium on the role of the vestibular organs in space exploration. NASA report SP-115, pp 99-116.

Spoendlin H (1970) Auditory, vestibular, olfactory and gustatory or- 
gans. In: Ultrastructure of the peripheral nervous system and sense organs (Bischoff A, ed), pp 173-338. St. Louis: Mosby.

Spoendlin HH, Gacek RR (1963) Electron-microscopic study of the afferent and efferent innervation of the organ of Corti of the cat. Ann Otol Rhinol Laryngol 56:660-686.

Tanaka M, Takeda N, Senba E, Tohyama M, Kubo T, Matsunaga T (1989) Localization, origin and fine structure of calcitonin generelated peptide-containing fibers in the vestibular end-organs of the rat. Brain Res 504:31-35.

Warr WB (1975) Olivocochlear and vestibular efferent neurons of the feline brain stem: their location, morphology and number determined by retrograde axonal transport and acetylcholinesterase histochemistry. J Comp Neurol 161:159-182.

Warr WB, Guinan JJ Jr (1979) Efferent innervation of the organ of Corti: two separate systems. Brain Res 173:152-155.

Warr WB, Guinan JJ Jr, White JS (1986) Organization of the efferent fibers: the lateral and medial olivocochlear systems. In: Neurobiology of hearing: the cochlea (Altschuler RA, Hoffman DW, Bobbin RP, eds), pp 333-348. New York: Raven.

Wersäll J (1956) Studies on the structure and innervation of the sensory epithelium of the cristae ampullaris in the guinea pig. A light and clectron microscopic investigation. Acta Otolaryngol (Stockh) [Suppl] 126:1-85.

Wersäll J, Bagger-Sjoback D (1974) Morphology of the vestibular sense organ. In: Handbook of sensory physiology, Vestibular system, Basic mechanisms, Vol 6 (Kornhuber HH, ed), pp 123-170. New York: Springer.

Wever EG (1974) The evolution of vertebrate hearing. In: Handbook of sensory physiology (Keidel WD, Neff WD, eds), pp 423-454. New York: Springer.

Wiederhold ML, Kiang NYS (1970) Effects of electric stimulation of the crossed olivocochlear bundle on single auditory-nerve fibers in the cat. J Acoust Soc Am 48:950-965. 